\title{
ANALISIS TINGKAT KENYAMANAN DI KOTA MANADO DAN WILAYAH PENYANGGANYA BERDASARKAN INDEKS THI (TEMPERATURE HUMIDITY INDEX)
}

\author{
ANALYSIS OF COMFORT LEVEL IN MANADO CITY AND THE TERRITORY \\ AREA BASED ON THI (TEMPERATURE HUMIDITY INDEX) \\ Wenas Ganda Kurnia' dan Sofian Widiyanto ${ }^{2 *}$ \\ ${ }^{1}$ Stasiun Pemantau Atmosfer Global Lore Lindu Bariri \\ ${ }^{2}$ Stasiun Klimatologi Minahasa Utara \\ *Email: widiyantosofian@gmail.com
}

Naskah masuk: 12 Juni 2020, Naskah diperbaiki: 15 Juli 2020, Naskah diterima: 20 Juli 2020

\section{ABSTRAK}

Sebagai salah satu Provinsi yang menjadi pusat perekonomian di Kawasan Indonesia Timur, Sulawesi Utara menjadi tujuan bagi para perantau. Tumbuh pesatnya perkembangan pembangunan diberbagai sektor mengakibatkan semakin berkurangnya ruang terbuka hijau dan juga dapat menyebabkan terjadinya masalah sosial dan masalah lingkungan sehingga dapat menyebabkan ketidaknyamanan suatu wilayah. Tujuan dari penyusunan indeks kenyamanan ini adalah untuk mengetahui seberapa besar tingkat kenyamanan di Kota Manado sebagai pusat perekonomian Sulawesi Utara dan kabupaten/kota penyangganya menggunakan metode Temperature Humidity Index (THI). Data yang digunakan dalam penelitian ini adalah data suhu udara dan kelembaban udara harian tahun 2008-2017 dari Stasiun BMKG di Sulawesi Utara. Indeks THI umumnya hanya sebagian populasi $(28.15 \%)$ perkotaan merasakan Nyaman dan pada kategori Sebagian Nyaman dengan rata-rata sebesar $59.97 \%$. dan kategori Tidak Nyaman terjadi sebesar $11.87 \%$. Tingkat kenyamanan yang paling rendah dirasakan oleh penduduk Kota Bitung sedangkan perasaan nyaman di ruangan terbuka dirasakan oleh penduduk Kabupaten Minahasa. Kecenderungan peningkatan indeks THI terjadi hampir di semua kota kecuali Kota Bitung dengan laju terbesar dialami oleh kota Manado.

Kata kunci: Tingkat Kenyamanan Termal, Temperature Humidity Index, Sulawesi Utara

\begin{abstract}
As one of the provinces that is the center of the economy in Eastern Indonesia, North Sulawesi is a destination for migrants. The rapid growth of development in various sectors cause a reduction in green open space and can also cause social problems and environmental problems that can cause inconvenience of an area. The preparation of this comfort index was made to find out how much the comfort level was in several districts/cities in North Sulawesi using the Temperature Humidity Index (THI) method. The data used in this study are daily air temperature and humidity data for 20082017 from BMKG station in North Sulawesi. The $\mathrm{THI}$ index is generally only a portion of the population $(28.15 \%)$ of cities felt comfortable and in the category of Most Comfortable with an average of $59.97 \%$. and the Uncomfortable category occurred at $11.87 \%$. The lowest level of comfort felt by residents of the City of Bitung while feeling comfortable in the open space felt by residents of Minahasa Regency. The increasing trend of the $\mathrm{THI}$ index occurs in almost all cities except Bitung City with the largest rate experienced by the city of Manado.
\end{abstract}

Keywords: Thermal Comfort Level, Temperature Humidity Index, North Sulawesi 


\section{Pendahuluan}

Sulawesi Selatan dan Sulawesi Utara sebagai dua provinsi di wilayah Indonesia timur yang memiliki daya saing tertinggi [1]. Ekonomi Sulawesi Utara tahun 2019 tumbuh 5,66\%. Dari sisi produksi, pertumbuhan didorong oleh hampir seluruh lapangan usaha, dengan pertumbuhan tertinggi dicapai lapangan usaha jasa lainnya yang tumbuh $15,75 \%$ [2]. Provinsi Sulawesi Utara mempunyai 15 kabupaten/kota yakni Kabupaten Bolaang Mongondow, Kabupaten Bolaang Mongondow Selatan, Kabupaten Bolaang Mongondow Timur, Kabupaten Bolaang Mongondow Utara, Kabupaten Kepulauan Sangihe, Kabupaten Kepulauan Siau Tagulandang Biaro, Kabupaten Kepulauan Talaud, Kabupaten Minahasa, Kabupaten Minahasa Selatan, Kabupaten Minahasa Tenggara, Kabupaten Minahasa Utara, Kota Bitung, Kota Kotamobagu, Kota Manado dan Kota Tomohon [3].

Kota Manado sebagai ibu kota provinsi dan pusat perekonomian menjadikan kota terbesar kedua di Sulawesi setelah Makassar [2]. Sebagai pusat perekonomian di Sulawesi Utara, tentunya Manado menjadi tujuan bagi para perantau, dengan banyaknya para perantau yang datang dari tahun ketahun tak khayal menjadikan wilayah Manado semakin sesak dan berimbas ke kabupaten/kota di sekitarnya terutama dalam kasus alih fungsi lahan pertanian menjadi pemukiman [3]. Tumbuh pesatnya perkembangan pembangunan di berbagai sektor yang dapat mengakibatkan semakin berkurangnya ruang terbuka hijau (RTH) dan juga dapat menyebabkan terjadinya masalah sosial dan masalah lingkungan [4]. Masalah lingkungan yang terjadi yaitu perubahan lingkungan yang dapat membawa dampak terhadap perubahan unsur iklim. Perubahan unsur iklim yang terjadi adalah suhu, penerimaan radiasi matahari, kecepatan angin, dan keawanan. Diantara unsur-unsur tersebut yang dapat dirasakan langsung perubahannya adalah suhu udara [5]. Perubahan suhu udara yang terjadi ini semakin meningkat dari hari ke hari dan akhirnya akan mempengaruhi kenyamanan manusia [6].

Temperature Heat Index (Indeks Kenyamanan) merupakan suatu metode yang dapat digunakan untuk mengkaji tingkat kenyamanan di suatu daerah. Dari metode ini dihasilkan suatu indeks untuk menetapkan efek dari kondisi panas pada kenyamanan manusia yang mengkombinasikan antara unsur suhu dan kelembaban [5]. Fenomena meningkatnya suhu rata-rata di suatu daerah yang tinggi biasanya disebut dengan pulau panas (heat island). Panas yang dihasilkan biasanya berasal dari proses pembakaran, sisa pembuangan gas kendaraan bermotor, aktivitas manusia maupun jenis bahan bangunan tertentu [5]. Peningkatan suhu udara yang mengakibatkan berkurangnya rasa kenyamanan pada suatu daerah, kondisi seperti ini kurang menguntungkan bagi manusia dalam melakukan aktifitasnya sebab produktifitas kerja manusia cenderung menurun atau rendah pada kondisi udara yang tidak nyaman seperti halnya terlalu dingin atau terlalu panas. Produktifitas kerja manusia meningkat pada kondisi suhu yang nyaman [7]. Indeks kenyamanan THI dapat dibedakan menjadi dalam tiga kondisi yaitu, kondisi nyaman berada pada kisaran nilai $\mathrm{THI}$ 19-23, kondisi sedang berada pada kisaran nilai THI 23-27 dan untuk kisaran nilai THI di atas 27 dinyatakan sebagai kondisi yang tidak nyaman [8]. Selain indeks kenyamanan berdasar Temperature Heat Index, ada juga yang dinamakan dengan Indeks Suhu Basah dan Bola (ISBB), ISBB adalah pengukuran temperatur lingkungan dilakukan dengan mengukur komponen temperatur yang terdiri dari suhu kering, suhu basah alami, dan suhu radiant. Selain itu juga perlu dilakukan pengukuran terhadap kelembaban udara relatif dan kecepatan angin [9].

Dalam penelitian ini objek wilayah penelitian bukan hanya kota-kota besar seperti penelitian yang terdahulu namun kabupaten/kota penyangga ibu kota juga dijadikan objek penelitian. Fokus dan tujuan dari penelitian ini adalah untuk mengetahui tingkat kenyamanan di Kota Manado, Kota Bitung, Kabupaten Minahasa Utara dan Kabupaten Minahasa secara bulanan dan kecenderungan tingkat kenyamanan dari tahun ke tahun menggunakan indeks kenyamanan THI dengan batas kenyamanan $[10,11]$ seperti apa yang telah dimodifikasi untuk iklim tropis [4].

\section{Metode Penelitian}

\section{Lokasi Penelitian.}

Penelitian ini dilakukan wilayah Provinsi Sulawesi Utara, tepatnya di Kota Manado, Kota Bitung, Kabupaten Minahasa Utara dan Kabupaten Minahasa dimana Kota Manado sebagai pusat perekonomian di Sulawesi Utara serta Kota Bitung, Kabupaten Minahasa Utara dan Kabupaten Minahasa sebagai daerah penyangga ibu kota. Lokasi penelitian dan letak geografis terlihat dalam Gambar 1 dan Tabel 1 


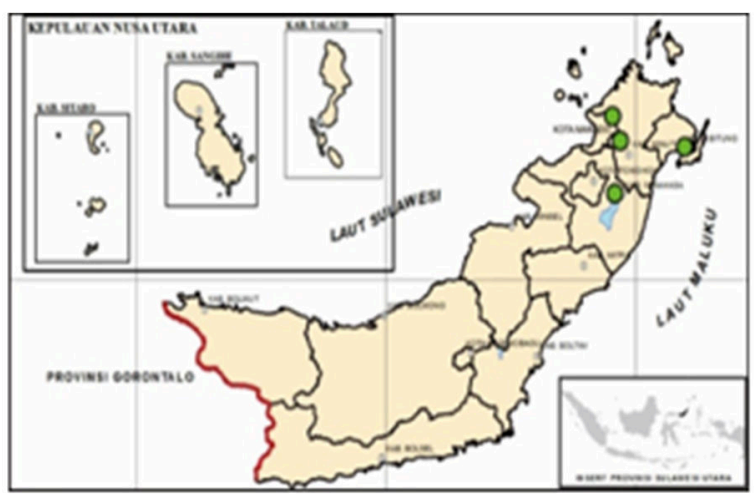

Gambar 1. Lokasi penelitian.

Tabel 1. Letak geografis lokasi penelitian.

\begin{tabular}{cccc}
\hline $\begin{array}{c}\text { Nama } \\
\text { Stasiun }\end{array}$ & Lintang & Bujur & $\begin{array}{c}\text { Elevasi } \\
(\mathbf{m})\end{array}$ \\
\hline $\begin{array}{c}\text { Stasiun } \\
\text { Meteorologi } \\
\text { Manado }\end{array}$ & 1.545 & 124.925 & 80 \\
$\begin{array}{c}\text { Stasiun } \\
\text { Meteorologi } \\
\text { Bitung }\end{array}$ & 1.443 & 125.18 & 3.5 \\
$\begin{array}{c}\text { Stasiun } \\
\text { Klimatologi } \\
\text { Minahasa } \\
\text { Utara }\end{array}$ & 1.498 & 124.898 & 85 \\
$\begin{array}{c}\text { Pos } \\
\text { Peofisika } \\
\text { Tondano }\end{array}$ & 1.295 & 124.925 & 704 \\
Minahasa & & & \\
\hline
\end{tabular}

Data. Data yang digunakan dalam penelitian ini adalah data suhu udara dan kelembaban udara harian tahun 2008-2017 di Stasiun Meteorologi Sam Ratulangi Manado, Stasiun Meteorologi Bitung, Stasiun Klimatologi Minahasa Utara dan Pos Geofisika Tondano Minahasa.

Metode. Analisa tingkat kenyaman dinyatakan dalam indeks kenyamanan yaitu Temperature Humidity Indeks (THI) merupakan suatu indeks dengan satuan derajat celcius sebagai besaran yang dapat dikaitkan dengan tingkat kenyamanan yang dirasakan populasi manusia di wilayah perkotaan. Indeks kenyamanan dihitung dengan menggunakan rumus [10] sebagai berikut;

$$
\begin{array}{ll} 
& \text { THI }= \\
& \mathbf{0 . 8} \mathbf{T}+\{(\mathbf{R H x T}) / \mathbf{5 0 0}\} \\
\mathrm{T} & : \text { suhu udara }\left({ }^{\circ} \mathrm{C}\right), \\
\mathrm{RH} & : \text { kelembapan relatif } \\
\mathrm{THI} & : \text { indeks kenyamanan }\left({ }^{\circ} \mathrm{C}\right)
\end{array}
$$

Batas kenyamanan menggunakan selang kenyamanan yang dimodifikasi untuk iklim tropis $[4,10,11]$ pada nilai $\mathrm{THI}$ antara $21-24{ }^{\circ} \mathrm{C}$ terdapat $100 \%$ populasi menyatakan nyaman, THI antara $25-27{ }^{\circ} \mathrm{C}$ hanya $50 \%$ populasi merasa nyaman, serta pada $\mathrm{THI}>27{ }^{\circ} \mathrm{C}$ sebanyak $100 \%$ populasi merasa tidak nyaman. Analisis tren THI dalam penelitian ini menggunakan tren linier. Analisis tren digunakan untuk melihat pergerakan data yang menunjukkan arah perkembangan menuju ke satu titik (cenderung naik/turun).

\section{Hasil dan Pembahasan}

Analisis tingkat kenyamanan di Sulawesi Utara menggunakan data suhu dan kelembaban relatif rata-rata bulanan di empat titik wilayah di Sulawesi Utara berdasarkan perhitungan diperoleh persentase frekuensi kejadian tingkat kenyamanan yang dikategorikan pada tiga tingkat kenyamanan yaitu Nyaman, Sebagian Nyaman dan Tidak Nyaman [10]. Seperti yang terlihat pada Gambar 2. Tingkat kenyamanan di Kota Manado yang diwakili oleh titik pengamatan di Stasiun Meteorologi Sam Ratulangi Manado menunjukan Kota Manado periode 2008-2017 hari Nyaman 5,7\% (209 hari), Sebagian Nyaman $87 \%$ (3177 hari) dan Tidak Nyaman 7,3\% (267 hari) serta analisis pertahun Nyaman 21 hari/tahun, Sebagian Nyaman 318 hari/tahun, Tidak Nyaman 27 hari Itahun

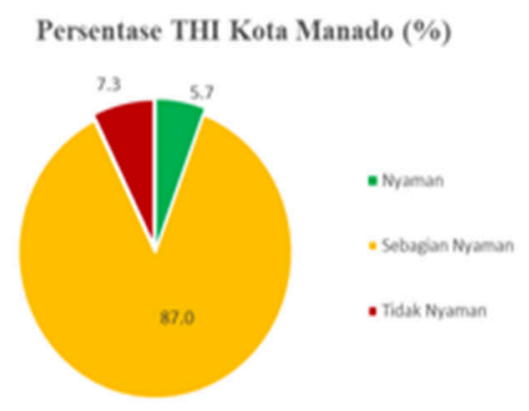

Gambar 2. Tingkat kenyamanan di Manado.

Tingkat kenyamanan di Kota Bitung yang diwakili oleh titik pengamatan di Stasiun Meteorologi Bitung seperti yang terlihat pada Gambar 3. Menunjukan Kota Bitung periode 2008-2017 hari Nyaman 0,1\% (4 hari), Sebagian Nyaman 62,4\% (2280 hari) dan Tidak 
Nyaman $37,5 \%$ (1368 hari) serta analisis pertahun Nyaman 0 hari/tahun, Sebagian Nyaman 228 hari/tahun, Tidak Nyaman 137 hari/tahun. Jika dilihat berdasarkan faktanya, letak Stasiun Meteorologi Bitung berada di dekat pantai dan Kota Bitung sendiri adalah sebagai kota pelabuhan terbesar di Sulawesi Utara.

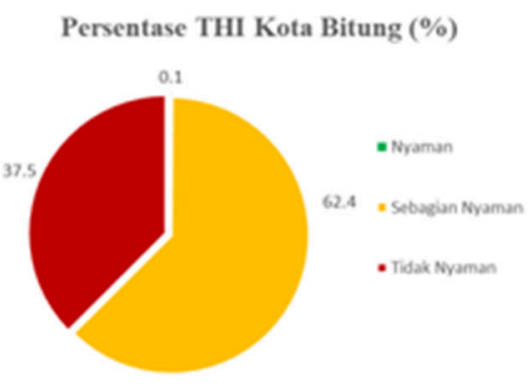

Gambar 3. Tingkat kenyamanan di Bitung.

Jika dilihat dari Gambar 4. Tingkat kenyamanan di Kabupaten Minahasa Utara yang diwakili oleh titik pengamatan di Stasiun Klimatologi Minahasa Utara menunjukan Kabupaten Minahasa Utara periode 2008-2017 hari Nyaman 6,9\% (252 hari), Sebagian Nyaman 90,4\% (3304 hari) dan Tidak Nyaman 2,7\% (98 hari) serta analisis pertahun Nyaman 25 hari/tahun, Sebagian Nyaman 330 hari/tahun, Tidak Nyaman 10 hari/tahun.

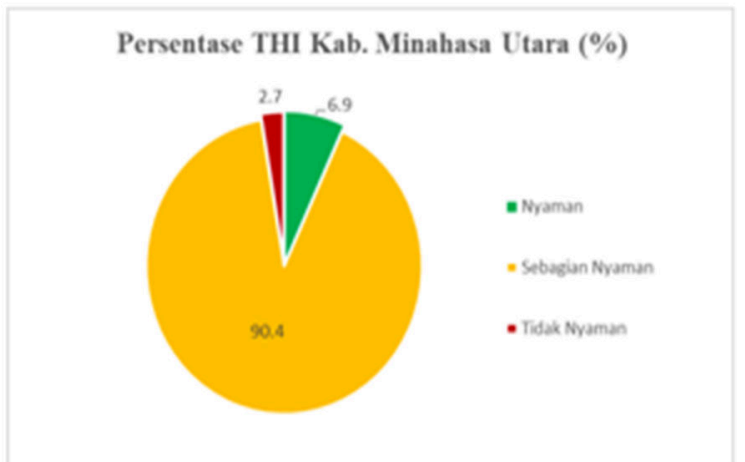

Gambar 4. Tingkat kenyamanan di Minahasa Utara.

Tingkat kenyamanan di Kabupaten Minahasa yang diwakili oleh titik pengamatan di Pos Geofisika Tondano Minahasa seperti yang terlihat pada Gambar 5. Menunjukan Kabupaten Minahasa periode 2008-2017 hari Nyaman 99,9\% (3510 hari) dan Sebagian Nyaman $0,1 \%$ (5 hari) serta analisis pertahun Nyaman 351 hari/tahun dan Sebagian Nyaman 1 hari/tahun.

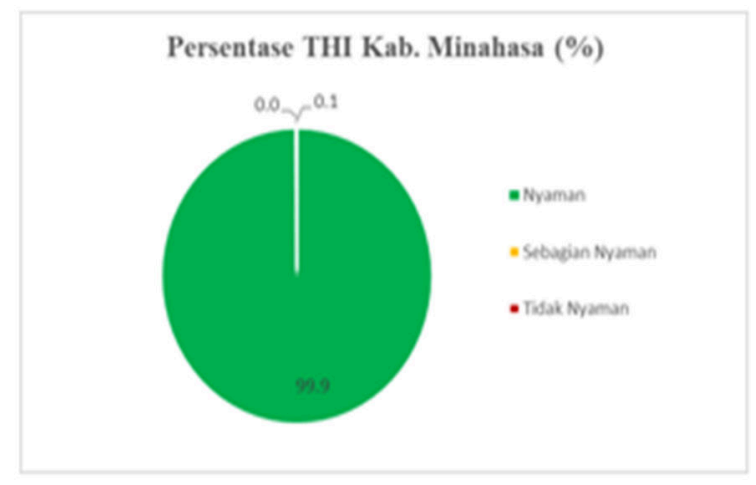

Gambar 5. Tingkat kenyamanan di Minahasa.

THI bulanan secara klimatologis pada Gambar 6. menunjukkan pola yang bimodal dengan puncak terjadi pada bulan Mei dan Oktober dan THI terendah terjadi pada bulan Juli dan Agustus. Hal ini sesuai dengan pola yang ditunjukkan oleh suhu udara di masing-masing kabupaten/kota. Kota Bitung memiliki THI bulanan yang tertinggi dibandingkan kota lainnya dengan rata-rata berkisar $26,7^{\circ} \mathrm{C}$ dan terendah terjadi di kabupaten Minahasa dengan rata-rata berkisar $22,3{ }^{\circ} \mathrm{C}$. Hal ini sejalan dengan sifat klimatologis dari suhu udara dan kelembapan relatif di kedua kabupaten/kota tersebut.

Berdasarkan Gambar 7, 8, 9, 10. Nilai THI tahunan cenderung meningkat dari tahun ke tahun selama periode 2008-2017 hampir di semua kota/kabupaten di wilayah penelitian kecuali Kota Bitung yang menunjukkan penurunan nilai THI. Peningkatan nilai THI terbesar setiap tahunnya terjadi di Kota Manado sebesar $0,07{ }^{\circ} \mathrm{C} /$ tahun atau $0,7^{\circ} \mathrm{C} / 10$ tahun dan diikuti oleh Kabupaten Minahasa Utara sebesar $0.025{ }^{\circ} \mathrm{C} /$ tahun atau $0,25{ }^{\circ} \mathrm{C} / 10$ tahun. Selanjutnya, nilai THI meningkat sebesar $0,01{ }^{\circ} \mathrm{C} /$ tahun atau $0,1{ }^{\circ} \mathrm{C} / 10$ tahun terjadi di Kabupaten Minahasa. Sedangkan THI cenderung menurun di Kota Bitung dengan nilai yang kecil yaitu berkisar $0,018{ }^{\circ} \mathrm{C} /$ tahun atau $0,18^{\circ} \mathrm{C} / 10$ tahun.

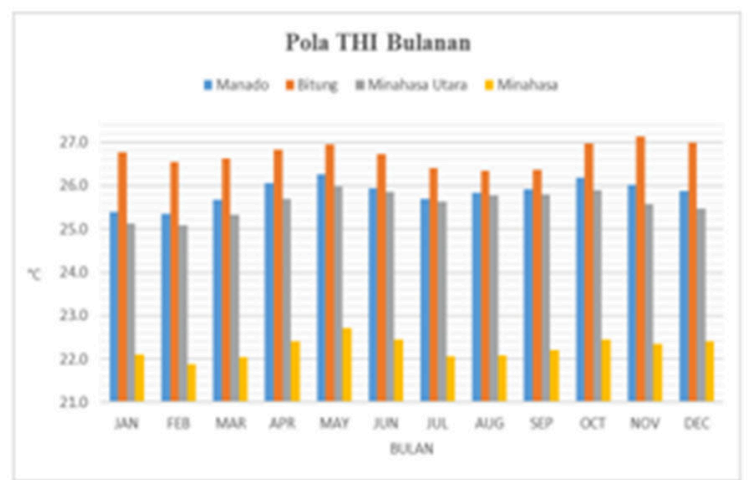

Gambar 6. Pola bulanan THI Sulawesi Utara. 


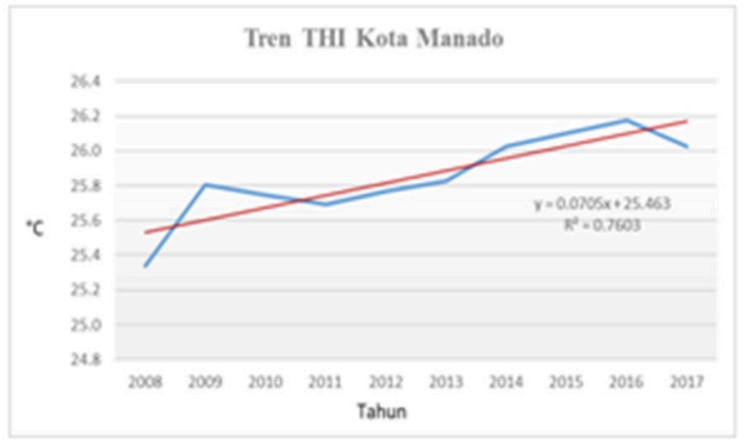

Gambar 7. Tren THI Manado.

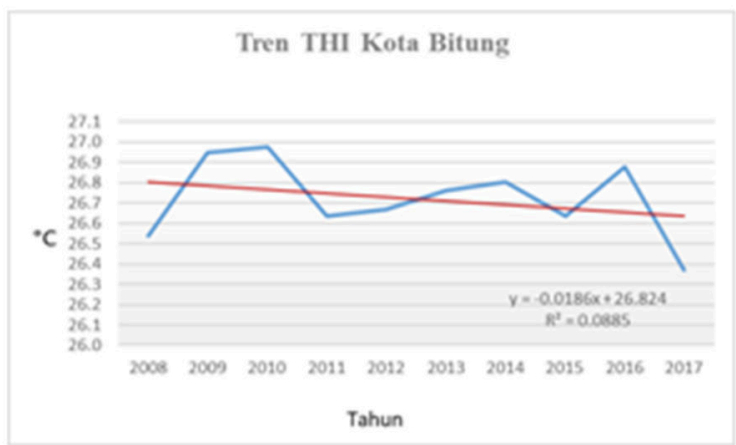

Gambar 8. Tren THI Bitung.

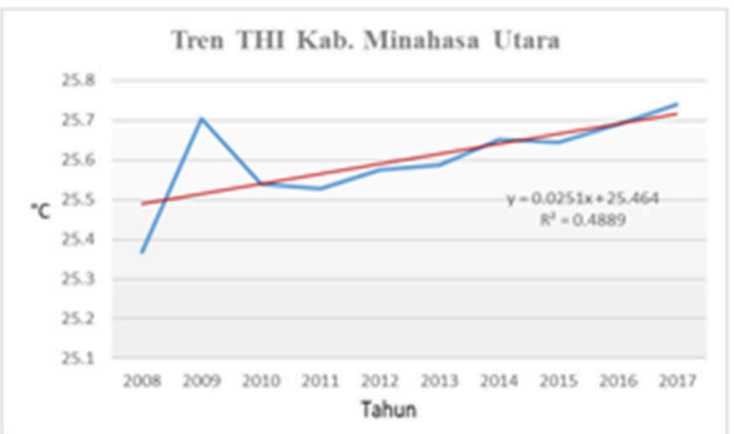

Gambar 9. Tren THI Minahasa Utara.

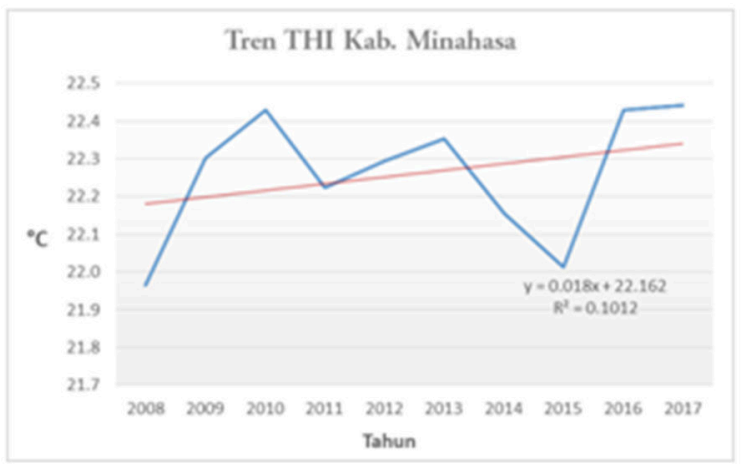

Gambar 10. Tren THI Minahasa.

Terjadinya kecenderungan peningkatan nilai THI salah satunya disebabkan oleh semakin tingginya laju perkembangan urbanisasi di wilayah perkotaan. Perubahan penggunaan lahan umumnya dipengaruhi oleh baik faktor alam seperti karakteristik geografis dan tanah dan faktor sosial ekonomi seperti pertumbuhan penduduk, perencanaan pembangunan, pengaturan penggunaan lahan, penzonaan dan peraturan lainnya yang terkait $[11,12]$. Perubahan penutupan lahan akan mengubah sifat-sifat fisis permukaan seperti albedo, emisivitas, dan kekasapan permukaan yang berakibat mengubah panas yang diterima pada permukaan tersebut. Implikasinya adalah apabila suatu penutup lahan terkonversi dari lahan bervegetasi dan badan air menjadi menjadi daerah non vegetasi seperti pemukiman akan menyebabkan semakin meluasnya daerah panas dan kering. Apabila kondisi ini berlanjut akan menyebabkan tingkat kenyamanan akan berkurang menjadi tidak nyaman [5].

\section{Kesimpulan}

Setelah dilakukan analisis, secara klimatologis, rata-rata persentase tingkat kenyamanan termal harian menggunakan indeks THI di Manado, Bitung, Minahasa Utara dan Minahasa umumnya hanya sebagian populasi $(28,15 \%)$ perkotaan merasakan Nyaman dan pada kategori Sebagian Nyaman dengan rata-rata sebesar 59,97\%. dan kategori Tidak Nyaman terjadi sebesar $11,87 \%$. Tingkat kenyamanan yang paling rendah dirasakan oleh penduduk Kota Bitung sedangkan perasaan nyaman di ruangan terbuka dirasakan oleh penduduk Kabupaten Minahasa. Kecenderungan peningkatan indeks THI terjadi hampir di semua kota kecuali Kota Bitung dengan laju terbesar dialami oleh kota Manado. Taraf signifikansi > $50 \%$ terjadi di Kota Manado. Bitung dan Kabupaten Minahasa Utara sehingga tingkat kenyamanan dari tahun ke tahun semakin tidak nyaman di ketiga kota tersebut.

\section{Saran}

Bagi penulis lain yang ingin melanjutkan penelitian ini, atau membuat penelitian yang sama di tempat lain agar mencari data yang lebih panjang agar hasil semakin representatif. Analisis THI di Manado dan kota/kabupaten penyangganya ini dapat dimanfaatkan sebagai pertimbangan penambahan Ruang Terbuka Hijau (RTH) di wilayah tersebut. Selain itu dapat digunakan juga sebagai pertimbangan dalam perancangan dan desain bangunan perkotaan yang menyesuaikan dengan kenyamanan manusia yang bermukim. 


\section{Daftar Pustaka}

[1] K. H. Tan, N. Merdikawati, M. Amri, K. Y. Tan. (2016). Analisis Daya Saing Provinsi Dan Wilayah Menjaga Momentum Pertumbuhan. World Scientific.

[2] Badan Pusat Statistik. (2020, Juni 11). Provinsi Sulawesi Utara Pertumbuhan Ekonomi 2019. Retrived from https://sulut.bps.go.id/pressrelease/2020 /02/05/698/pertumbuhan-ekonomisulawesi-utara-2019--.html,

[3] Badan Pusat Statistik. (2020, Juni 11) . Provinsi Sulawesi Utara Sulawesi Utara Dalam Angka 2019. Retrived from https://sulut.bps.go.id/publication/2019/0 8/16/bbc7a944cf4fece77fc29a86/provins i-sulawesi-utara-dalam-angka-2019.html,

[4] S. Effendy. (2007). Keterkaitan Ruang Terbuka Hijau dengan Urban Heat Island Wilayah Jabodetabek. Disertasi, Institut Pertanian Bogor, Bogor.

[5] Y. Kalfuadi, (2009). Analisis temperature heat index dalam hubungannya dengan ruang terbuka hijau Studi Kasus Kabupaten Bungo - Provinsi Jambi. Skripsi, FMIPA. Institut Pertanian Bogor, Bogor.

[6] T. Honjo. (2009). Thermal comfort in outdoor environment. Global environmental research, 13, 43-47.

[7] F, Idealistina. (1991). Model Termoregulasi Tubuh untuk Penentuan Besaran Kesan Thermal Terbaik dalam kaitannya dengan Kinerja Manusia. Tesis, Institut Teknologi Bandung, Bandung.

[8] M. Wirasmita., dkk. (2003). Aplikasi Iklim Terhadap Perkembangan Urban. Metropolitan.

[9] A. Alam, Purwitasari, D. N. Widhawati, R. Fardiansyah, A. R. Tualeka. (2014). Factors Related to Subjective Complaint of Heat Pressures in Employees Basement Mtc Karebosi Makassar. International Refereed Journal of Engineering and Science, Volume 3, Issue 12. PP.49-54.

[10] Nieuwol, S. (1977). Tropical climatology. London: Wiley.

[11] Emmanuel, R. (2004). Thermal comfort implications of urbanization in a warmhumid city: The Colombo Metropolitan Region (CMR), Sri Lanka. J Build Environm. 40:1591-1601.

[12] E. Rustiadi, D. O. Pribadi, A. E. Pravitasari, G. S. Indraprahasta, and L. S. Iman. (2014). Urban Development Challenges, Risks and Resilience in Asian Mega Cities. Springer. 